\title{
OVERVIEW OF A RESEARCH ON ACTUATORS CONTROL FOR BETTER SEAKEEPING IN FAST SHIPS
}

\author{
J.M. Giron-Sierra, S. Esteban, J. Recas, B. Andres,-Toro, J.M. De la Cruz \\ J.M. Riola ${ }^{1}$, J. Aranda ${ }^{2}$, F. Velasco ${ }^{3}$ \\ Dep. A.C.Y.A., Fac. CC. Fisicas. Universidad Complutense de Madrid, 28040 Madrid. Spain \\ e-mail: gironsi@dacya.ucm.es \\ ${ }^{l}$ CEHIPAR, El Pardo. Madrid. Spain. \\ ${ }^{2} U N E D, 28040$ Madrid. Spain. \\ ${ }^{3}$ Universidad de Cantabria, Santander. Spain.
}

\begin{abstract}
The paper is an overview of a research initiated seven years ago by three groups of three universities, under the auspices of a Spanish shipbuilder. The research aims to improve the seakeeping performances of fast ferries, by using moving appendages such transom flaps and T-foil. There is a problem of control design to move the actuators in adequate way, to counteract the effect of encountered waves. The research focuses on alleviation of seasickness. Several aspects have been covered along the research, motivating a long series of papers. The overview gives an ordered account of the main results, with the corresponding references. Main results concerning seasickness and navigation, prediction of seasickness during ship design, experimental modelling, control design and experimental verification, are presented. . Copyright $\mathbb{C}$ 2005 IFAC
\end{abstract}

Keywords: Overview, Ship control, Seakeeping, Human factors.

\section{INTRODUCTION}

With the advent of fast ferries the need of seakeeping improvement systems was realized. In particular, seasickness of passengers needs to be minimized. Scientific studies on seasickness, such (O'Hanlon and Mc Cauley, 1974), relate it to oscillatory vertical accelerations with a frequency around $1 \mathrm{rad} / \mathrm{sec}$. Seakeeping improvement is also of military interest, looking for better crew and ship operational efficiency.

Years ago, under the auspices of a Spanish shipbuilder, a research started on the use of actuators such T-foil and transom flaps. The actuators should move to counteract the effect of encountered waves, alleviating the accelerations that cause sickness. A research team, of three universities, was formed to study the effect of such actuators and to control them. The research started considering head seas, letting for a second step the more general case of any heading with respect to waves.

The research has been fruitful, with many publications. Then, it seems useful to make now an overview of the results, highlighting the main aspects and pointing to the adequate references for more details. The name given to the research is CRIBAV (In Spanish:"Control Robusto e Inteligente de Barcos de Alta Velocidad” ). A web page (CRIBAV, 1999) was established with videos of experiments.

In general, control studies begin with modelling, taking a long time, especially if there are experiments. Indeed, this has been the case in this research. Moreover, control designs have been also verified by experiments too. This paper starts with a description of the problem and its scientific context. Then, it focuses on the modelling task, beginning with data gathering. The paper continues with control design aspects. Then, the paper deals with present research 
activities, considering the 6 DOF case. Finally, conclusions are presented, with a view of future advances.

\section{THE PROBLEM OF SEAKEEPING IMPROVEMENT USING ACTUATORS}

Classically the main motion control topics concerning ships are related to the rudder. Simply because in many ships, the rudder is the only actuator for motion control. There are few papers in the scientific literature considering other actuators. However, it is interesting to quote some early initiatives on the use of antipitching fins (Abkowitz, 1959; Stefun, 1959; Vugts, 1967 ). Only recently some papers about moving appendages appeared, in connection with fast ferries (Haywood, et al., 1995; Ryle, 1998; WuQiang and Zhu-Shun, 2002; Sclavounos and Borgen, 2004).

Figure 1 shows the case considered by CRIBAV. It is $126 \mathrm{~m}$. long fast ferry, aluminium made, deep-V monohull, capable of 40 knots speed (Anonymous, 1996). Two transom flaps and a T-foil near the bow were added to the ship.

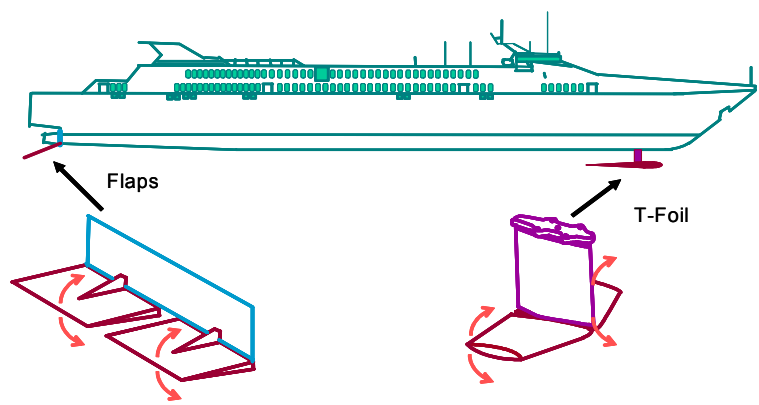

Fig. 1. Location of actuators on the ship

A first look to the control problem shows important peculiarities. The input causing ship motions are waves. When the ship's speed changes, added masses change, the frequency of encounter with waves shifts, and resonance peaks of the motions shift also. The plant to control is non-linear. Ship motions are coupled.

To simplify the research, three fixed ship's speeds were considered: 20, 30 and 40 knots. Regular sea waves were approximated as sinusoidal. This paves the way to consider transfer functions.

With head seas, only pitch and heave motions are relevant for the research (surge do not cause vertical accelerations).

Pitch moments and heave forces caused by sea waves are enormous. The actuators have limited authority, being unable to completely eliminate the vertical motions.
Driving a car on certain roads could lead to vertical oscillations around $1 \mathrm{rad} / \mathrm{sec}$., causing sickness. It can be avoided changing the speed. Same with ships (they can also change the heading).

An analogy of three filters can be established to calculate the percent of passengers becoming sick (Ewing and Goodrich, 1967). There are statistical descriptions of sea waves, according with a classification of sea states which tabulates ten different cases, from calm waters (Sea State Number 0 , abbreviated as SSN 0), to phenomenal waves more than $14 \mathrm{~m}$ high (SSN 9). The statistical distributions of waves across wave frequencies can be modelled as band-pass filters (one for each sea state). The vertical motions of the ship depend on the input frequency as another band-pass filter. Finally, the mathematical model of seasickness established in (O'Hanlon and Mc Cauley, 1974) can be seen as a band-pass filter, around $1 \mathrm{rad} / \mathrm{sec}$. When the three filters have in common a certain frequency band, passengers become sick.

Based in the three filters analogy, a complete study of the impact of ship's speed and heading on passengers' seasickness has been done (Esteban, et al., 2005). This study has been preceded by a paper (GironSierra, et al., 2003a) considering in general a ship, the wave wavelengths, and the speed and heading conditions putting the ship in resonance with excitation. This type of studies is useful for operational advice, to suggest changes in navigation parameters to avoid large motions and seasickness.

An interesting result has been derived in (GironSierra, et al., 2004a), making possible to compute the percent of passengers becoming sick after two hours of sailing in certain conditions of sea state and ship's speed, using the frequency response of the ship (vertical accelerations). This frequency response can be determined from simulation tools, based on a CAD description of the ship's hull, before the ship was actually built. Consequently, it is possible to provide a tool helping to design ships with better seakeeping performances.

The result obtained is given by the following equation:

$$
M S I=100 \cdot e^{-0.42(S I A-0.5)}
$$

where MSI (Motion Sickness Incidence) is the percent of passengers becoming sick after two hours of sailing, and SIA (Seasickness Impact Area) is the area of the of the frequency response of the coupled three filters.

Figure 2 shows the frequency response of the three filters for SSN5 and 40 knots ship speed. The figure includes the coupling of the three filters.

\section{THREE FILTERS}




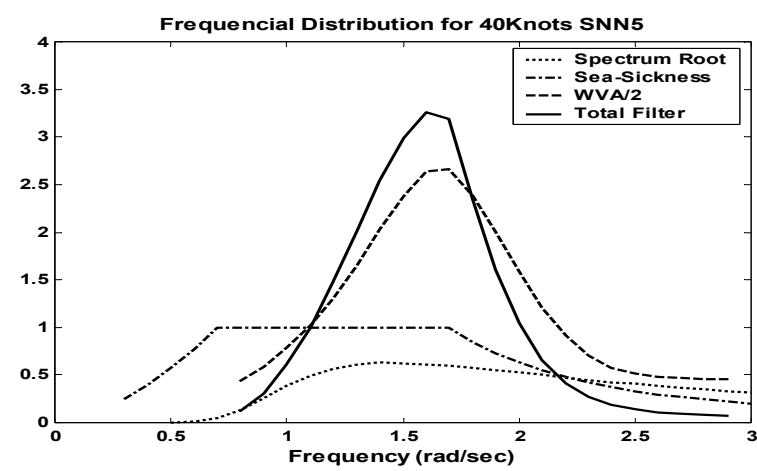

Fig. 2. The three filters and their intersection

A main result of the studies devoted to the three filters analogy, is to determine the frequencies of interest for actuators and control.

\section{GETTING DATA FOR SHIP MOTION MODELLING}

The research is based on two sources of data about ship motions in response to waves. One is a simulation program that, using a CAD description of the hull, gives the added masses, and the magnitude and phase of surge, heave, sway, roll, heave and yaw motions, together with the magnitude and phase of surge, heave and sway forces, and sway, roll and yaw moments. The program computes that information for regular waves. In this research a set of 25 wavelengths were selected, covering the frequencies of interest.

The other source of information is experimental. A $1 / 25$ scaled down replica of the fast ferry was built. With the help of a large experimental facility ("CEHIPAR: Canal de Experiencias Hidrodinamicas de El Pardo") near Madrid, several series of experiments were carried on, using a $150 \mathrm{~m}$ x $30 \mathrm{~m}$ basin with a wavemaker. The replica was attached to a computerized planar motion carriage. Part of the experiments was devoted to reproduce the same cases treated by the simulation program: head seas, regular waves, 25 different wavelengths. Figure 3 shows photographs of the experimental facility and the replica:

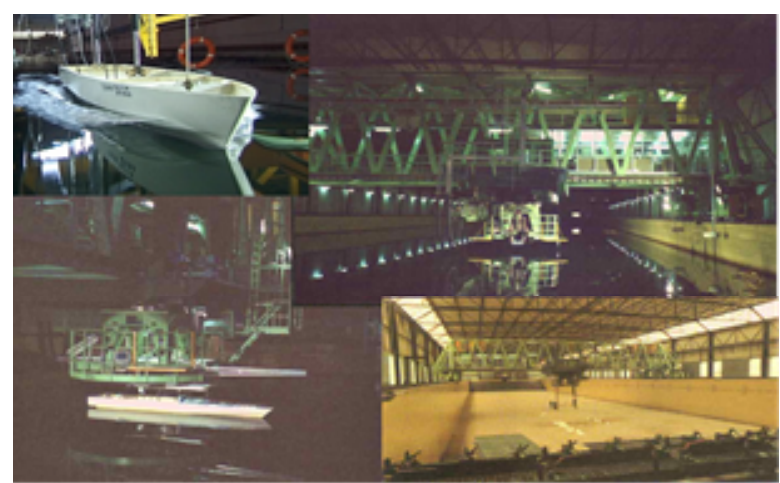

Fig 3. The CEHIPAR facility and the replica
The computerized towing carriage is equipped with instrumentation for video recording, and for measurement of forces, moments and motions experienced by the replica. There are more details of the research design and the experiments in (GironSierra, et al., 2001; De la Cruz, et al., 2001).

\section{MODEL OF SHIP VERTICAL MOTIONS}

The modelling task was initiated by using experimental data and standard identification methods (De la Cruz, et al., 1998). However it provides little insight, and brings some interpretation uncertainties.

A basis for first principles modelling of the ship motions is given by the following equations (Lloyd, 1998; Fossen, 2002):

$$
\begin{aligned}
& \left(m+a_{11}\right) \ddot{x}_{1}+b_{11} \dot{x}_{1}=F_{1} \\
& \left(m+a_{22}\right) \ddot{x}_{2}+b_{22} \dot{x}_{2}+ \\
& \quad+a_{24} \ddot{x}_{4}+b_{24} \dot{x}_{4}+a_{26} \ddot{x}_{6}+b_{26} \dot{x}_{6}+c_{26} x_{6}=F_{2} \\
& \left(m+a_{33}\right) \ddot{x}_{3}+b_{33} \dot{x}_{3}+c_{33} x_{3}+ \\
& \quad+a_{35} \ddot{x}_{5}+b_{35} \dot{x}_{5}+c_{35} x_{5}=F_{3} \\
& a_{42} \ddot{x}_{2}+b_{42} \dot{x}_{2}+\left(I_{44}+a_{44}\right) \ddot{x}_{4}+b_{44} \dot{x}_{4}+c_{44} x_{4}+ \\
& \quad+a_{46} \ddot{x}_{6}+b_{46} \dot{x}_{6}+c_{46} x_{6}=F_{4} \\
& a_{53} \ddot{x}_{3}+b_{53} \dot{x}_{3}+c_{53} x_{3}+\left(I_{55}+a_{55}\right) \ddot{x}_{5}+ \\
& \quad+b_{55} \dot{x}_{5}+c_{55} x_{5}=F_{5} \\
& a_{62} \ddot{x}_{2}+b_{62} \dot{x}_{2}+a_{64} \ddot{x}_{4}+b_{64} \dot{x}_{4}+ \\
& \quad+\left(I_{66}+a_{66}\right) \ddot{x}_{6}+b_{66} \dot{x}_{6}+c_{66} x_{66}=F_{6}
\end{aligned}
$$

The equations suggest a model decomposition that is very convenient for control studies. Figure 4 shows a block diagram of the model structure, for pitch and heave motions. The Wave-to-Forces (or moments) blocks correspond to the right hand side of the equations. The Forces (or moments)-to-Motions blocks correspond to the left hand side of the equations.

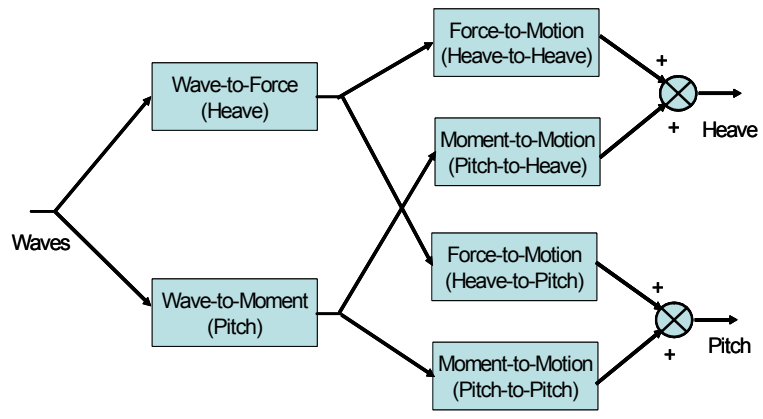

Fig 4. Block diagram of the model

Notice that the left hand side equations give enough information to establish transfer functions for the Forces-to-Motions blocks. However, the transfer functions for the Waves-to-Forces must be obtained by fitting data (obtained by simulation or 
experiments). An interesting way for modelling is the use of Genetic Algorithms, as it is described in (De Andres, et al., 2000; Aranda, et al., 2000). In (Esteban, et al., 2004b) a detailed procedure to obtain all transfer functions is described.

\section{ACTUATORS}

The dimensions, characteristics and location of the flaps and the T-foil were given by the technical advice of the Spanish shipbuilders. Not much was in the literature as a help for modelling the actuators. Therefore, they were considered as submerged wings, and the corresponding non-linear equations were considered. Scaled down flaps and T-foil were added to the replica. A series of experiments in a long channel established the lift force due to these actuators at several angles of attack. The parameters of the equations were fitted to the data, with good agreement. This part of the research is described in (Giron-Sierra, et al., 2002).

Figure 5 shows the expected efficiency of the actuators at ship's speeds of 20, 30 and 40 knots, eliminating part of the vertical accelerations (Esteban, et al., 2000b).
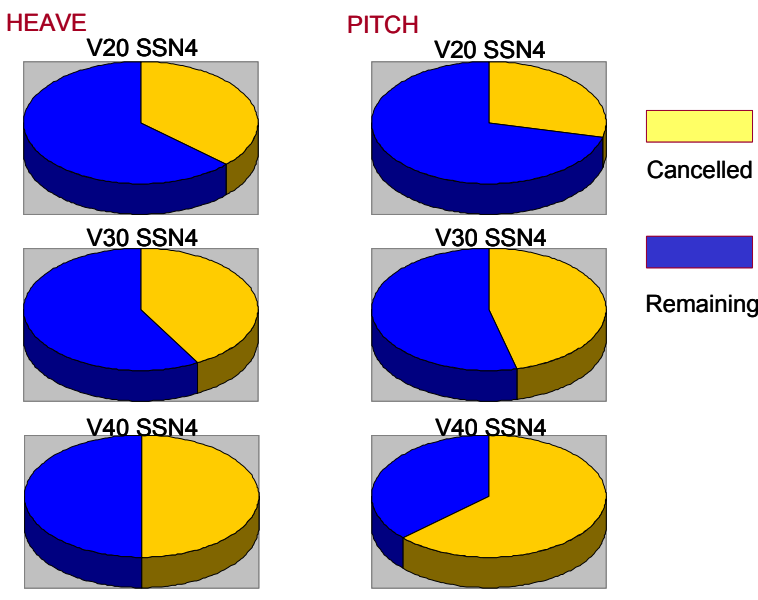

Fig. 5. Vertical accelerations cancelled by actuators

A Simulink model was established, taking into account the motion rate and maximum angle limits and the dynamic response of hydraulic cylinders (Esteban, et al., 2000a).

Recently, part of the research studied the implications of other dimensions and locations of the actuators (Esteban, et al., 2004a). It is possible to increase the actuators efficiency.

\section{CONTROL DESIGN}

Taking advantage of the model structure, controller and actuators blocks can be easily included. In this way, a simulation environment for control design studies has been built, using Simulink (Esteban, et al., 2000c; 2001a, 2001b).
Since seasickness is caused by vertical accelerations, it is natural to consider the use of accelerometers. With head seas, the worst place for the passenger, where vertical accelerations are larger, is near the bow. An accelerometer is placed there, to measure the WVA (the Worst Vertical Acceleration). The target for the control of actuators is to minimize the WVA.

For practical reasons, the first controller to be studied is the PID. This controller has been put into the simulation environment, and the tuning of the PID has been systematically explored. Integral action has negative effects, so only the PD is useful. Figure 6 shows in $3 \mathrm{D}$ the effect of different PD parameters on WVA, for the flaps and for the T-foil (De la Cruz, et al., 2004).
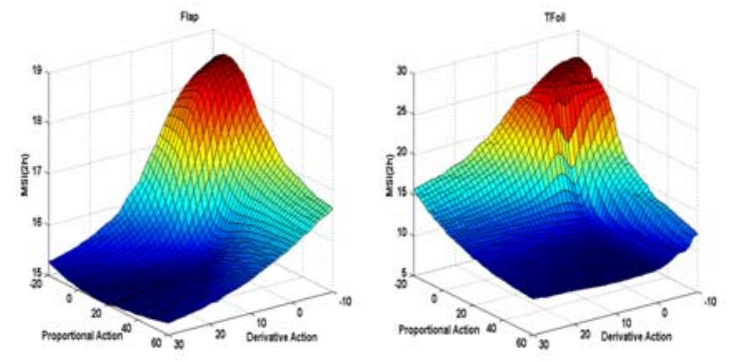

Fig. 6. Best tuning of the PD (T-foil and flaps)

A multivariable PD, based on heave and pitch measurement, has been considered in (Aranda, et al., 2001).

The research on control design continues exploring several alternatives. One is the application of QFT (Aranda, et al. 2004; Velasco, et al., 2004). Another proceeds with multiobjective optimisation (Esteban, et al., 2002). Predictive features have been investigated in (Esteban, et al., 2001c). And the alternative of non-linear control is considered in (Esteban, et al., 2003), with recent results in (Esteban, et al., 2004a).

An automatic code generation tool has been developed, for fast and easy experimental study of any control strategy (Polo, et al, 2001). Using this tool on the field, at CEHIPAR, several experiments have been done to verify the good result of the controlled moving actuators (Giron-Sierra, et al., 2001). Figure 7 shows the results for 40 knots and SSN5.

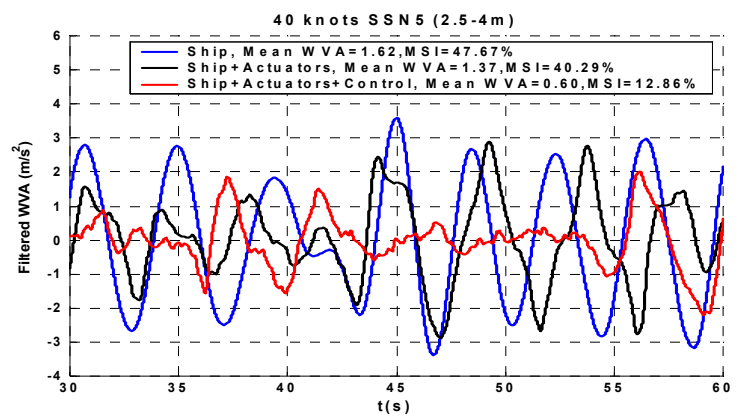

Fig. 7. Effect of the controlled actuators 


\section{MORE GENERAL HEADING CONDITIONS}

The more general case of any heading with respect to waves is now under study. There are headings not possible to handle in the experimental facility, so open air experiments should be done. A new, smaller (1/40 scaled) replica is being developed (GironSierra, et al., 2003c; Recas, et al., 2004b). Since this replica will not be towed, a set of new sensors must be included on-board, together with scaled down waterjets and a distributed control system. In other words, this is an autonomous small ship.

Starting form the data furnished by the simulation program, a 6DOF model of the ship motions is under development (Giron-Sierra, et al., 2003b, 2004). Guidelines for decoupled control design, in the frequency domain, are obtained.

The experiments with the new replica have already started. The first series of experiments is devoted to check the autonomous features of the replica. First control designs will be experimentally verified in the immediate future.

\section{CONCLUSIONS}

This paper presents an overview of a research on the improvement of seakeeping in fast ferries, using moving actuators such flaps and T-foil. Main results have been presented, with references for more details.

The research has an experimental basis, confirming good expectations from the use of flaps and T-foil.

At present, the research deals with more general 6DOF problems, with a lot of coupling. Experiments require a new system, with an autonomous replica.

Other aspects for the future are to study structural effects of the actuators. New actuators such interceptors and thrusters must also be considered.

\section{ACKNOWLEDGMENTS}

The authors want to thank the support of the CICYT Spanish Committee (projects DPI2000-0386-C03-02, and DPI2003-09745-C04-02), and the collaboration of the CEHIPAR staff and the advice of IZAR. Likewise, thanks to other members of the research team: J. Aranda, F. Velasco, M. Santos, J.M. Diaz, P. Ruiperez, E. Besada, O.R. Polo, R. Muñoz Mansilla, P. Perez de Lucas, A. Maron, T.M. Rueda, E. Lopez, and E. Moyano.

\section{REFERENCES}

Abkowitz, M.A. (1959). The effect of antipitching fins on ship motion, SNAME Trans., vol 67, 210252.

Anonymous (1996). 126m long Spanish fast ferry launched, Fast Ferries, September, 19-20.
Aranda, J., J.M. De la Cruz, J.M. Diaz, B. De Andres Toro, P. Ruiperez, S. Esteban and J.M. GironSierra (2000). Modelling of a high speed craft by non-linear squares method with constraints, In Proceedings IFAC Intl. Symposium Maneuvering and Control of Marine Craft MCMC2000, Aalborg, 227-232.

Aranda, J., J.M. Diaz, P. Ruiperez, T.M. Rueda and E. Lopez (2001). Decreasing of the motion sickness incidence by a multivariable classic control for a high speed ferry, In Proceedings IFAC Intl. Conf. Control Applications in Marine Systems CAMS2001, Glasgow.

Aranda, J., R. Muñoz-Mansilla and J.M. DiazMartinez (2004). The problem of the coupling of the vertical movement control with roll movement in fast ferries, In Proceedings IFAC Intl. Conf. Control Applications in Marine Systems CAMS2004, Ancona, Italy.

CRIBAV (1999). Web site: ctb.dia.uned.es

De Andres Toro, B., S. Esteban, J.M. Giron-Sierra and J.M. De la Cruz (2000). Modelling the motions of a fast ferry with the help of genetic algorithms, In Proceedings Third IMACS MATMOD, Vienna, 783-786.

De la Cruz, J.M., J. Aranda, P. Ruiperez, J.M. Diaz and A. Maron (1998). Identification of the vertical plane motion model of a high speed craft by model testing in irregular waves, In Proceedings IFAC Intl. Conf. Control Applications in Marine Systems CAMS 1998, Fukuoka, Japan.

De la Cruz, J.M., P. Perez de Lucas, J. Aranda, J.M. Giron-Sierra, F. Velasco and A. Maron (2001). A research on motion smoothing of fast ferries, In Proceedings IFAC Intl. Conf. Control Applications in Marine Systems CAMS2001, Glasgow.

De la Cruz, J.M., J. Aranda, J.M. Giron-Sierra, F. Velasco, S. Esteban, J.M. Diaz, B. De Andres (2004). Improving the comfort of a fast ferry with the control of flaps and T-foil, IEEE Control Systems Magazine, vol. 24, n. 2, April, 47-60.

Esteban, S., J.M. De la Cruz, J.M. Giron-Sierra, B. De Andres, J.M. Diaz and J. Aranda (2000a). Fast ferry vertical acceleration reduction with active flaps and T-foil, In Proceedings IFAC Intl. Symposium Maneuvering and Control of Marine Craft MCMC2000, Aalborg, 233-238.

Esteban, S., J.M. De la Cruz, J.M. Giron-Sierra and B. De Andres Toro (2000b). Frequency-domain model of fast ferry vertical motions, In Proceedings RINA Intl. Conf. Hydrodynamics of High Speed Craft, London, paper 18, 1-8.

Esteban, S., J.M. Giron-Sierra, B. De Andrees and J.M. De la Cruz (2000c). A computer-based testbed for designing the control of vertical motions of a fast ferry, In Proceedings MARSIM 2000, Orlando, USA., 79-83.

Esteban, S., B. De Andres, J.M. Giron-Sierra, O.R. Polo and E. Moyano (2001a). A simulation tool for a fast ferry control design, In Proceedings 
IFAC Intl. Conf. Control Applications in Marine Systems CAMS2001, Glasgow.

Esteban, S., B. De Andres, J.M. De la Cruz and J.M. Giron-Sierra (2001b). Smoothing fast ferry vertical motions: a simulation environment for control analysis, In Proceedings EUROSIM 2001 Congress, Delft.

Esteban, S., J.M. Giron-Sierra, J.M. De la Cruz and B. De Andres (2001c). Predictive perturbation cancelling for seakeeping improvement of a fast ferry, In Proceedings European Control Conference 2001, Oporto, Portugal.

Esteban, S., B. Andres-Toro, E. Besada-Portas, J.M. Giron-Sierra and J.M. De la Cruz (2002). Multiobjective control of flaps and T-foil in high speed ships, In Proceedings IFAC 2002 World Congress, Barcelona.

Esteban, S., J.M. Giron-Sierra and J.M. De la Cruz (2003). Nonlinear control design for fast ships, In Proceedings 13th Intl. Ship Control Systems Symposium, Orlando, USA.

Esteban, S., J.M. Giron-Sierra, J. Recas, J.M. Riola, B. De Andres and J.M. De la Cruz (2004a). Actuators and control design for fast ferry using seasickness analysis, In Proceedings IFAC Intl. Conf. Control Applications in Marine Systems CAMS2004, Ancona, Italy.

Esteban, S., J.M. Giron-Sierra, B. De Andres, J.M. De la Cruz and J.M. Riola (2004b). Fast ships models for seakeeping improvement studies using flaps and T-foil, J. Ship Research, September.

Esteban, S., J.M. Giron-Sierra, B. De Andres, J.M. De la Cruz (2005). Frequency domain analysis for prediction of seasickness on ships, Marine Technology.

Ewing, J.A. and G.J. Goodrich (1967). The influence on ship motions of different wave spectra and the ship length, Trans. RINA, 109, 47-63.

Fossen, T.I. (2002). Marine Control Systems, Marine Cybernetics AS, Trondheim.

Giron-Sierra, J.M., S. Esteban, B. De Andres, J.M. Diaz and J.M. Riola (2001). Experimental study of controlled flaps and T-foil for comfort improvement of a fast ferry, In Proceedings IFAC Intl. Conf. Control Applications in Marine Systems CAMS2001, Glasgow.

Giron-Sierra, J.M., R. Katebi, J.M. De la Cruz, and S. Esteban. (2002). The control of specific actuators for fast ferry vertical motions damping, In Proceedings IEEE Intl. Conf. CCA/CACSD, Glasgow.

Giron-Sierra, J.M., B. Andres-Toro, S. Esteban, J. Recas, E. Besada and J.M. De la Cruz (2003a). Model based analysis of seasickness in a fast ferry. In Proceedings IFAC MCMC 2003, Gerona, Spain.

Giron-Sierra, J.M., B. Andres-Toro, S. Esteban, J. Recas, E. Besada, J.M. De la Cruz and A. Maron (2003b). First principles modelling study for the development of a 6 DOF motions model of a fast ferry. In Proceedings IFAC MCMC 2003, Gerona, Spain.
Giron-Sierra, J.M., S. Esteban, J. Recas, B. De Andres, E. Besada, J.M. De la Cruz and J.M. Riola (2003c). Distributed electronic system for monitoring and control of a fast ship. In Proceedings IEEE IECON 2003, Roanoke, USA.

Giron-Sierra, J.M., B. De Andres, S. Esteban, J.M. Riola, J. Recas and J.M. De la Cruz (2004a). New results about model based study of seasickness in fast ferries, In Proceedings IFAC Intl. Conf. Control Applications in Marine Systems CAMS2004, Ancona, Italy.

Giron-Sierra, J.M., B. De Andres, S. Esteban, J. Recas, J.M. De la Cruz and J.M. Riola (2004b). Advances in the 6DOF motions model of a fast ferry, In Proceedings IFAC Intl. Conf. Control Applications in Marine Systems CAMS2004, Ancona, Italy.

Haywood, A.J., A.J. Duncan, K.P. Klaka and J. Bennet (1995). The development of a ride control system for fast ferries, Control Engineering Practice, 695-703.

Lloyd, A.R.J.M. (1998). Seakeeping: Ship Behaviour in Rough Weather, A.R.M.J. Lloyd, Gosport, Hampshire, U.K.

O'Hanlon, J.F. and M.E. McCauley (1974). Motion sickness incidence as a function of frequency and acceleration of vertical sinusoidal motion, Aerospace Medicine.

Polo, O.R., J.M. De la Cruz, J.M. Giron-Sierra and S. Esteban (2001). EdRoom. Automatic C++ code generador for real time systems modelled with Room, In Proceedings IFAC Intl. Conf. New Technologies for Computer Control, Seoul.

Wu-Qiang, L. and D. Zhu-Shun (2002). Reducing the vertical motion in waves of round-bildge boat with controllable transom flaps. Intl. Shipbuilding Progress, vol.49, n.1, 37-51.

Recas, J., J.M. Giron-Sierra, S. Esteban, B. De Andres, J.M. De la Cruz and J.M. Riola (2004). Autonomous fast ship physical model with actuators for 6DOF motion smoothing experiments, In Proceedings IFAC Intl. Conf. Control Applications in Marine Systems CAMS2004, Ancona, Italy.

Ryle, M. (1998). Smoothing out the ride, The Motor Ship, January, 23-26.

Sclavounos, P.D. and H. Borgen (2004). Seakeeping analysis of a high-speed monohull with a motioncontrol hydrofoil, J. Ship Research, vol.48, n.2, 77-117.

Stefun, G.P. (1959). Model experiments with fixed bow antipitching fins, J. Ship Research, vol.3, n.2, 15-23.

Velasco, F.J., T.M. Rueda, E. Lopez, and E. Moyano (2004). Pitch movement QFT control to reduce the MSI of a turbo ferry, In Proceedings IFAC Intl. Conf. Control Applications in Marine Systems CAMS2004, Ancona, Italy.

Vugts, J.H. (1967). Pitch and heave with fixed and controlled bow fins, Intl. Shipbuilding Progress, vol. 15, n.3, 191-215. 